\title{
Performance assessment of the Gash Delta Spate Irrigation System, Sudan
}

\author{
Araya Z. Ghebreamlak ${ }^{1}$, Haruya Tanakamaru ${ }^{1}$, Akio Tada ${ }^{1}$, Bashir M. Ahmed Adam ${ }^{2}$, and \\ Khalid A. E. Elamin ${ }^{2}$ \\ ${ }^{1}$ Graduate School of Agricultural Science, Kobe University, Nada-ku, Kobe 657-8501, Japan \\ ${ }^{2}$ Agricultural Research Corporation, Wad Medani, P.O. Box 126, Sudan
}

Correspondence: Araya Z. Ghebreamlak (araiag4@gmail.com)

Received: 6 June 2017 - Accepted: 22 August 2017 - Published: 1 February 2018

\begin{abstract}
The Gash Delta Spate Irrigation System (GDSIS), located in eastern Sudan with a net command area of 100000 ha (an area currently equipped with irrigation structures), was established in 1924. The land is irrigated every 3 years (3-year rotation) or every 2 years (2-year rotation) so that about 33000 or 50000 ha respectively can be cultivated annually. This study deals with assessing the performance of the 3- and 2-year rotation systems using the Monte Carlo simulation. Reliability, which is a measure of how frequently the irrigation water supply satisfies the demand, and vulnerability, which is a measure of the magnitude of failure, were selected as the performance criteria. Combinations of five levels of intake ratio and five levels of irrigation efficiency for the irrigation water supply of each rotation system were analysed. Historical annual flow data of the Gash River for 107 years were fit to several frequency distributions. The Weibull distribution was the best on the basis of the Akaike information criteria and was used for simulating the ensembles of annual river flow. The reliabilities and vulnerabilities of both rotation systems were evaluated at typical values of intake ratio and irrigation efficiency. The results show that (i) the 3-year rotation is more reliable in water supply than the 2-year rotation, (ii) the vulnerability of the 3-year rotation is lower than that of the 2-year rotation and (iii) therefore the 3 -year rotation is preferable in the GDSIS. The sensitivities of reliability and vulnerability to changes in intake ratio and irrigation efficiency were also examined.
\end{abstract}

\section{Introduction}

Spate irrigation is a type of surface irrigation in which floodwater from a seasonal river is diverted to a deep-soiled flat field and allowed to spread naturally under the influence of slope, soil type and surface roughness. It is an inefficient method of irrigation with little control of the water spreading over the field (James, 1988). Nonetheless, it is feasible when the following requirements are met (Zimmerman, 1966): (i) a large and flat area within the proximity of an intermittent stream is available; (ii) the soil of the area is deep with good permeability and high water-holding capacity; (iii) and a shallow stream requiring a low diversion structure exists near the area. Moreover, in arid and semi-arid environments, in addition to the difficulty of finding a suitable site for a reservoir, the classical approach to water management through water storage is not practical as very high sed- iments and evaporation loss would not justify the development of economically useful reservoirs (van Steenbergen et al., 2010). That is why spate irrigation is common in arid and semi-arid regions, typically in countries in the Middle East, North and East Africa, West Asia and parts of Latin America (van Steenbergen, 1997).

The Gash Delta Spate Irrigation System, hereafter abbreviated as the GDSIS, in Kassala state, eastern Sudan (Fig. 1) was established in 1924. Spate water from the Gash River with an average effective flood period of about 70 days is diverted through seven intake structures. As shown in Fig. 2, a network of seven main canals and 13 sub-canals conveys the diverted water to six irrigation blocks within a net command area of 100000 ha (Cole, 1989). The flow in these gravity canals is divided into distributary canals that directly supply agricultural fields through breaches in the canal banks from 


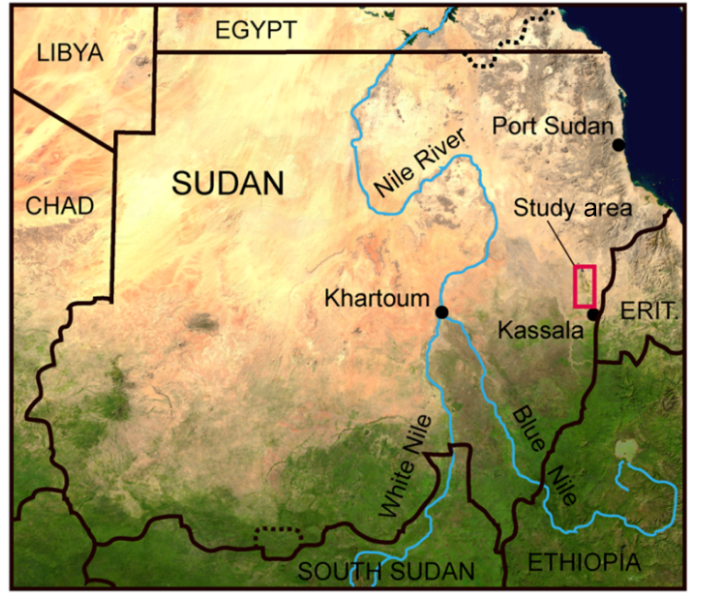

Figure 1. Location of the study area (source of satellite image: http: //www.maplibrary.org/).

which it spreads over the land with minimum further control (Swan, 1959).

Under the original plan, the land is irrigated every 3 years (3-year rotation) so that about 33000 ha of the 100000 ha can be cultivated annually. Each tenant previously cultivated 4.2 ha of cotton as a cash crop and 0.42 ha of sorghum for food self-sufficiency. The system functioned well when the number of tenants registered was about 10000 . Starting from the 1970s, the performance went into serious decline and was paralleled by droughts and civil unrest. Kassala state was settled with about $20 \%$ of the total refugees in Sudan, and as a result the number of GDSIS beneficiaries has increased fourfold. During the same period the cultivated area decreased by $50 \%$ owing to deterioration of the irrigation infrastructure (IFAD, 2004). Consequently, the land tenancy entitlement for each farmer is reduced considerably and farmers are allocated far less irrigated area than their entitlements. Under such conditions, the International Fund for Agricultural Development (IFAD) supported a programme for rehabilitation of the irrigation diversion structures in 2003. As a result, some changes were made, such as the change from a 3- to a 2 -year rotation system to accommodate more farmers. However, according to the evaluation reports by Anderson (2011), IFAD (2012) and IFAD (2014), the designed annual target irrigated area of the 2-year rotation (50 $000 \mathrm{ha}$ ) has never been realistic. Owing to a lack of detailed scientific studies and the complexity of the system, the above evaluation reports have not concretely articulated the reasons for the failure.

Despite the variability in the annual flow of the Gash River, the target irrigated areas of the 3- and 2-year rotations were decided on the basis of the average flow. This study investigates the irrigation water supply performance of the GDSIS through a Monte Carlo simulation by considering the stochastic nature of the Gash River flow. Moreover, the irrigation water supply, which determines the size of the irri-

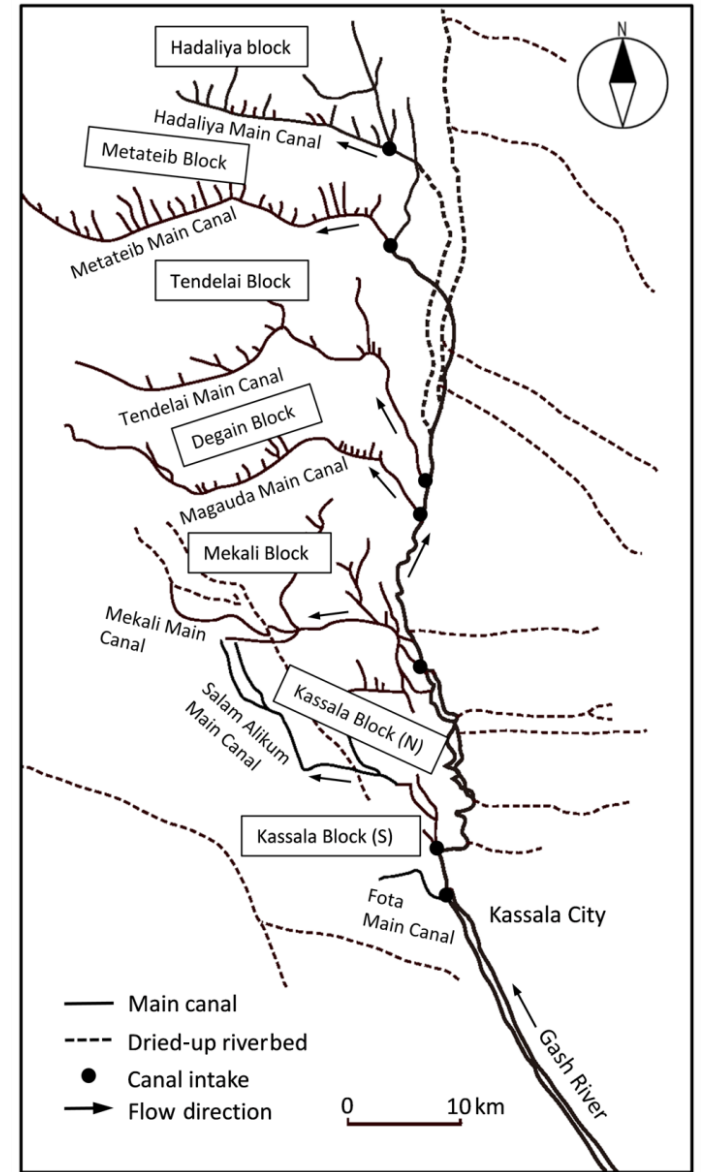

Figure 2. Schematics of the Gash Delta Spate Irrigation System (the original figure by Kirkby, 2001, was modified).

gated area, depends on the Gash River water allocation policy and capacity as well as the operation and efficiency of the irrigation structures. Hence, this study also deals with a parametric analysis of the effects of water allocation policy, planning and operation of the irrigation structures on the performance of the GDSIS. Towards this purpose, the proposed approach can be used to analyse different strategies for rehabilitation planning and operation policies and to select the best possible option.

\section{Data and simulation model}

\subsection{Annual flow data and statistics}

Analysis of the annual flow volume of the Gash River for 107 years (1907-2013) at Kassala Bridge, as shown in Fig. 3, was carried out to check for randomness and select the best fit probability density function.

The Gash River is a seasonal river, carrying water only during the rainy season from July to September. It is dry during the remaining months of the year. There is no flow carry-over from one year to the next. Moreover, a large part 


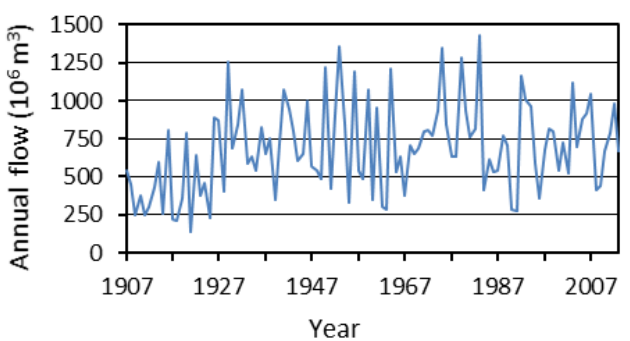

Figure 3. Annual flow of the Gash River measured at the Kassala Bridge gauging station (1907-2013; source: Gash Agricultural Scheme administrative office and Gash River training unit, Kassala).

of the river basin is in the semi-arid region. Thus annual flows in this river can be assumed as independent time series. The correlogram as depicted in Fig. 4 supports the above assumption.

The probability density functions commonly used in hydrology and water resources fall into three families. The first includes the normal and log-normal distributions. The second is the gamma and related distributions that include the exponential, log Pearson type III and beta distributions. The third family includes the extreme value distributions; special cases are the Gumbel and the Weibull distributions. In this study, normal, two- and three-parameter log-normal, twoand three-parameter gamma and two-parameter Weibull are tested.

Maximum likelihood method was used to estimate the parameter of each candidate. The chi-square test was used to check the goodness of fit at the $95 \%$ confidence interval, and all the tested distributions were found to be adequate. The Akaike information criteria (AIC) was used to rank the selected probability distributions. The two-parameter Weibull distribution was found to be the best. This superiority of the Weibull over the others is also indicated in the Q-Q plot of Fig. 5.

\subsection{Simulation model}

There are many ways of summarising time series performance data that might result from simulation analysis. The simple ways frequently used are the mean and variance (Hashimoto et al., 1982; Loucks and van Beek, 2005). However, the mean and variance usually fail to show how severe and how frequent periods of poor performance may be. Thus, other criteria, such as reliability and vulnerability, have gained popularity in water resources studies (Asefa et al., 2014; Jain, 2010; Jain and Bhunya, 2008; Kjeldsen and Rosbjerg, 2004), and these criteria are used in this study.

The reliability $(\alpha)$ is defined as the frequency or probability that a system $(X)$ is in a satisfactory state (Sat; Hashimoto et al., 1982). Therefore, the reliability of time series data can be defined as the amount of data in a satisfactory state $(S)$

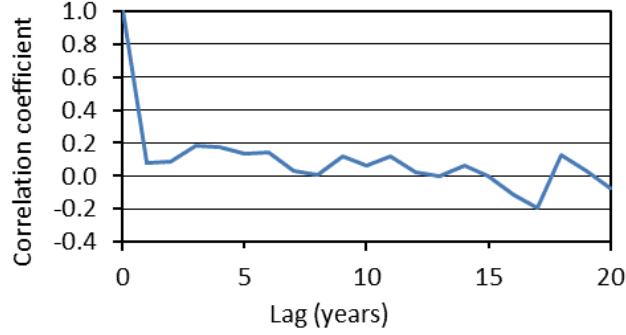

Figure 4. Correlogram of annual flow volume at Kassala Bridge (1907-2013).

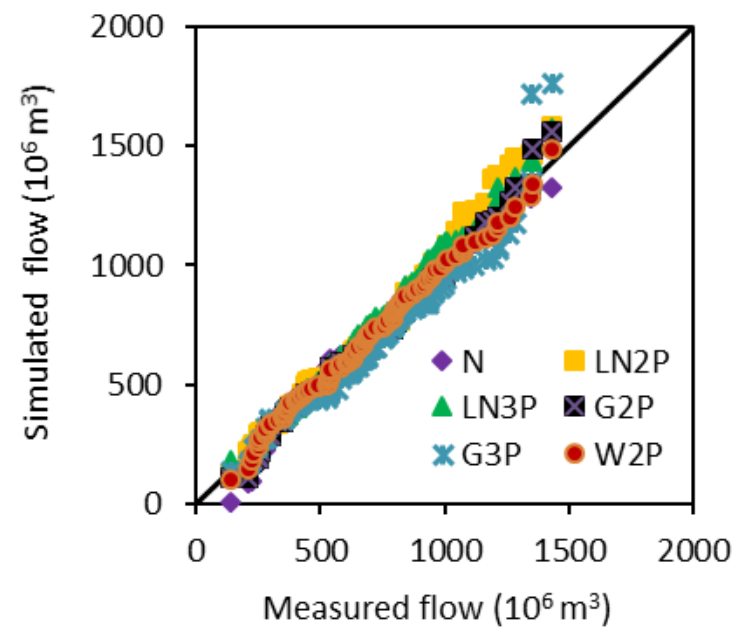

Figure 5. Q-Q plot of the selected probability density functions ( $\mathrm{N}=$ normal, $\mathrm{LN} 2 \mathrm{P}=$ two-parameter log-normal, LN3P $=$ threeparameter log-normal, G2P = two-parameter gamma, G3P = threeparameter gamma and $\mathrm{W} 2 \mathrm{P}=$ two-parameter Weibull).

divided by the total amount of data $(N)$ in the time series:

$\alpha(\%)=\operatorname{Prob}\{X \in \mathrm{Sat}\}=\frac{S}{N} \times 100$.

The vulnerability refers to the magnitude of a failure (here it is deficit, $D$ ) if one occurs. The expected value of vulnerability $v$ is given by Loucks and van Beek (2005):

$v=\frac{1}{N-S} \sum_{i=1}^{N-S} D_{i}$.

The mathematical descriptions of reliability and vulnerability are based on the assumption that the system under consideration at a given time is in either a satisfactory state or an unsatisfactory state. The focus of the current study is on an irrigation system. Hence, the satisfactory state occurs when the irrigation water supply is able to meet the irrigation water demand, and the unsatisfactory state occurs when the irrigation water supply is unable to meet the irrigation water demand.

For convenience of comparing the 3- and 2-year rotation systems, the original vulnerability of Eq. (2) is converted to 
a percentage of irrigation water demand (WD), and Eq. (3) is introduced as vulnerability in this study:

$v(\%)=\frac{1}{N-S} \sum_{i=1}^{N-S} \frac{D_{i}}{\mathrm{WD}} \times 100$.

To determine long-term performance criteria realistically, stochastic demand for and stochastic supply of water should be taken into account (Dudley et al., 1972). However, in this study, as the main target is to assess the performance of the 3- and 2-year rotation systems, hereafter abbreviated as $3 \mathrm{YR}$ and 2 YR systems, only the supply is considered stochastic. The demand is assumed as deterministic for two reasons: (i) the area is dominated by a single crop (sorghum) and (ii) the field is irrigated only once (before planting).

In addition to the annual volume of river flow, two parameters, namely intake ratio and irrigation efficiency, are considered for estimating the irrigation water supply. Intake ratio, as used here, refers to the fraction of river flow diverted to the GDSIS (volume of water diverted divided by total volume of river flow). The water allocation policies and practices of the GDSIS are such that 30 to $50 \%$ of the river flow is diverted for spate irrigation (Anderson, 2011; IFAD, 2014). Moreover, the intake ratio is also a function of the diversion structure capacity (e.g. total number of gates) and operation (e.g. number of gates opened during irrigation). In this paper, irrigation efficiency refers to the ratio of the average amount of water stored in the root zone to the average amount diverted from the river. Annual silt removal from canals and the redesigning of the canals to adjust to local changes and regimes are some of the factors that affect the irrigation efficiency. The typical intake ratio and irrigation efficiency in the study area are $40 \%$ (Anderson, 2011) and $50 \%$ (Abdelgadir, 2007).

The water diverted from the river via the diversion structures undergoes conveyance and application losses. The net irrigation water supply $\left(V_{\mathrm{s}}\right)$ is therefore a fraction of the diverted amount and is expressed as follows:

$V_{\mathrm{s}}=\mathrm{IE} \times \mathrm{IR} \times V_{\mathrm{r}}$,

where $V_{\mathrm{r}}$ is the annual river flow $\left(10^{6} \mathrm{~m}^{3}\right)$, IR is the intake ratio (decimal) and IE is the irrigation efficiency (decimal).

In this study, sorghum, the dominant crop based on the current cropping pattern in the GDSIS (Anderson, 2011), is considered. According to Doorenbos and Kassam (1979), the net crop water requirements of sorghum with a total growing period of 110 to 130 days are between 450 and $650 \mathrm{~mm}$. In spate irrigation in Sudan, an average of $500 \mathrm{~mm}$ net stored in the soil is used as the norm with a single watering per season (van Steenbergen et al., 2010). Hence, the net annual irrigation water demand for the 3YR (33000 ha) and 2YR (50000 ha) systems is about $165 \times 10^{6}$ and $250 \times 10^{6} \mathrm{~m}^{3}$ respectively.

Based on the above-mentioned conditions, a Monte Carlo simulation was performed on the evaluation of reliability and vulnerability using generated river flow. The whole simulation process, which was written in $\mathrm{R}$ programming language, can be summarised as follows.

Step 1 Ensembles of 100-year river flow were generated using the two-parameter Weibull distribution ignoring autocorrelation.

Step 2 Each river flow value was converted to net irrigation water supply using Eq. (4).

Step 3 Each net irrigation water supply value was compared with the irrigation water demand to determine the number of satisfactory states $(S)$ and deficits $\left(D_{i}\right)$; then the reliability and vulnerability were computed using Eqs. (1) and (3) respectively.

Step 4 Steps 1 to 3 were repeated 5000 times to determine the average and distribution of the selected criteria.

\section{Results and discussion}

\subsection{Reliability}

Initially, the Monte Carlo simulation was performed for the 3 YR and 2YR systems at typical values of intake ratio $(40 \%)$ and irrigation efficiency $(50 \%)$. The results, which reveal the distribution of irrigation water supply reliability of the $3 \mathrm{YR}$ and 2YR, are shown in Fig. 6. The mean reliability of the 3 YR system is about $54 \%$. This result is consistent with the qualitative assessment on the performance of the GDSIS by Ngirazie et al. (2015), which showed that the irrigation water supply is reliable to $53 \%$ of the farmers on average. When the annual target irrigated area is 50000 ha (2YR), the mean reliability decreases to $18 \%$. The low value of the reliability for the 2 YR reinforces the findings of other evaluation studies (e.g. Anderson, 2011; IFAD, 2012; IFAD, 2014) on the GDSIS rehabilitation, which state that the target area of 50000 ha was never realistic. As a result, the target irrigated area was changed from 50000 back to 33000 ha in 2008 according to the midterm progress report (IFAD, 2012).

The coefficients of variation for the reliabilities of the $3 \mathrm{YR}$ and $2 \mathrm{YR}$ are 0.09 and 0.21 respectively. This implies that the reliability of the $2 \mathrm{YR}$ system is not only very low, but also more uncertain. Therefore, in terms of reliability, the $3 \mathrm{YR}$ is much better than the $2 \mathrm{YR}$.

To test the sensitivity of the reliability to changes in the intake ratio (IR) and irrigation efficiency (IE), the Monte Carlo simulation was re-run for combinations of IR and IE. The resulting mean reliabilities are plotted in Fig. 7, which indicates that the reliability increases as the IR and IE increase. Although this trend is apparent without such analysis, the rate and amount of change is of practical interest for planners and decision makers. The mean reliability of the $3 \mathrm{YR}$ and $2 \mathrm{YR}$ systems for all IR and IE combinations varied from 0 to $91 \%$ and from 0 to $77 \%$ respectively. 


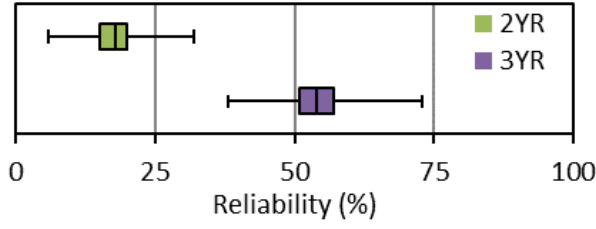

Figure 6. Box-whisker plots of the reliabilities of the $3 \mathrm{YR}$ (33000 ha) and 2YR (50000 ha) systems for typical values of intake ratio (IR) and irrigation efficiency (IE).

Relatively high reliability, greater than $60 \%$, can be attained for the 3 YR even for the low IR of $30 \%$ provided that the management of the system is good enough to achieve an IE of $70 \%$. This high value of reliability at a low IR may encourage planners and decision makers to invest more in improving the irrigation efficiency. However, such high reliability $(>60 \%)$ is unattainable in the $2 \mathrm{YR}$ unless the IR is greater than $50 \%$ for the same IE of $70 \%$. When the IR is very low, in this case $20 \%$, the reliability is less than 25 and $10 \%$ for the 3 YR and 2 YR respectively for all IEs considered.

For the typical value of IE (50\%), the mean reliability of the 3 YR and 2 YR varied from 3 to $80 \%$ and from 0 to $54 \%$ respectively. When the emphasis is on maintaining higher reliability, say $75 \%$ (the minimum standard value of irrigation system design in many countries), the IR has to be increased to more than $55 \%$ in the 3 YR system. This is unachievable in the 2YR even at the high IR of $60 \%$ under the typical IE. When the IR is kept constant at its typical value (40\%), the mean reliability of the 3YR and 2YR varied from 10 to $77 \%$ and from 0 to $48 \%$ respectively. The $75 \%$ reliability can only be achieved at the optimistically high IE of $70 \%$ and only for the 3YR.

Referring to Fig. 7, the reliability values of 75 and $50 \%$ for the 33000 and 50000 ha respectively can be achieved either by diverting $60 \%$ of the river flow or managing the irrigation system to a level of $70 \%$ IE. For both options, the increase in reliability would be accompanied by an increase in cost. However, the cost incurred for improving the IE can be compensated for by the value of the saved water. In fact, conserving water by improving the IE in irrigated agriculture can enhance equity among users. In contrast, the cost incurred by increasing the IR (through the expansion of irrigation structures) would be accompanied by reduced water availability to other sectors.

\subsection{Vulnerability}

As explained in Sect. 2.2, the Monte Carlo simulation of the vulnerability was conducted simultaneously and at the same IR and IE values as that of the reliability. The equivalent results are shown in Figs. 8 and 9. Figure 8 presents the distribution of the simulated vulnerabilities for the $3 \mathrm{YR}$ and $2 \mathrm{YR}$ systems for typical values of IR (40\%) and IE (50\%). As (a) 3YR (33000 ha)

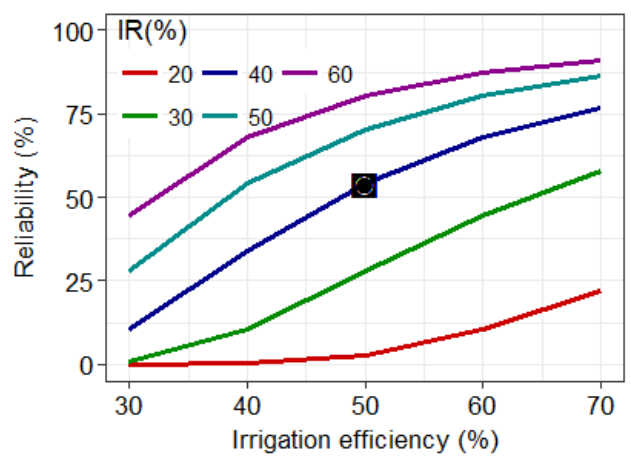

(b) 2YR (50000 ha)

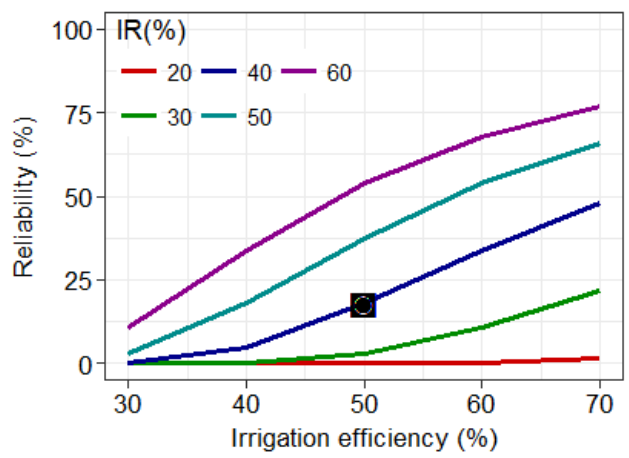

Figure 7. Mean reliability vs. irrigation efficiency (IE) at different levels of intake ratio (IR) of the 3- and 2-year rotation systems (the black square indicates typical values of IR and IE).

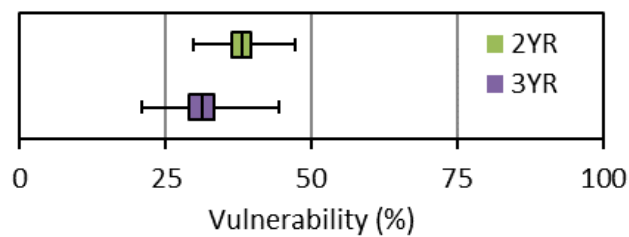

Figure 8. Box-whisker plots of the vulnerabilities of the $3 \mathrm{YR}$ (33000 ha) and 2YR (50000 ha) systems for typical values of intake ratio (IR) and irrigation efficiency (IE).

expected, the $2 \mathrm{YR}$ (irrigating $50000 \mathrm{ha}$ ) is more vulnerable than the 3 YR (irrigating $33000 \mathrm{ha}$ ). The mean vulnerabilities of the $3 \mathrm{YR}$ and $2 \mathrm{YR}$ are 31 and $38 \%$ respectively.

The mean vulnerabilities of the 3 YR and 2YR for all IR and IE combinations, as shown in Fig. 9, varied from 25 to $67 \%$ and from 28 to $77 \%$ respectively. Figure 9 shows that the mean vulnerability changes marginally with increasing IE when IR is greater than 30 and $40 \%$ for the $3 Y R$ and $2 Y R$ respectively. In both systems, the change in vulnerability is high for the $20 \%$ IR. This implies that for the small amount of water diverted when the irrigation efficiency is kept very low, e.g. $30 \%$, the vulnerability is about $65 \%$. If efforts were made to improve the IE to e.g. $60 \%$, the vulnerability would be improved to $40 \%$ ( $25 \%$ improvement). In contrast, for 
(a) 3YR (33000 ha)

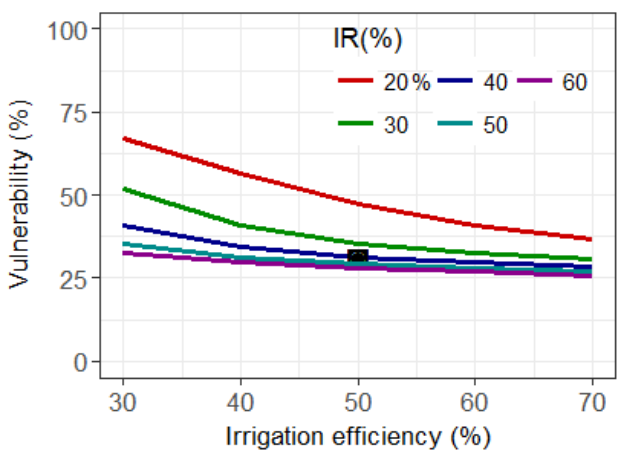

(b) 2 YR (50000 ha)

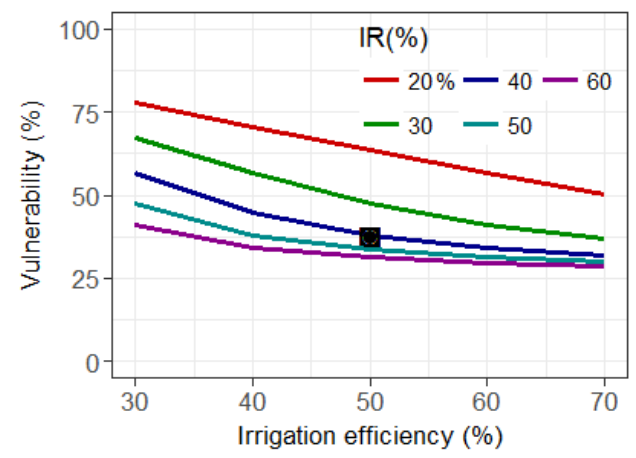

Figure 9. Mean vulnerability vs. irrigation efficiency (IE) at different levels of intake ratio (IR) of the 3- and 2-year rotation systems (the black square indicates typical values of IR and IE).

larger IR (e.g. $50 \%$ ), the corresponding change is only about $2 \%$. This implies that increasing the IR from 40 to $50 \%$ or $60 \%$ when the IE is greater than $40 \%$ does not improve the vulnerability significantly.

An important observation from Figs. 7 and 9 is that the difference in vulnerabilities of the $3 \mathrm{YR}$ and $2 \mathrm{YR}$ is small compared to their respective reliability differences. For example, for an IR of $40 \%$ and IE of $50 \%$, the reliability difference is $36 \%$, while the vulnerability difference is only $7 \%$. This indicates that in many years, the river flows, which are satisfactory in the $3 \mathrm{YR}$, are marginally unsatisfactory in the 2YR. For example, if one chooses to irrigate 50000 ha instead of 33000 ha, the increment in the average deficit of water is only $7 \%$. This result, despite the high frequency of failure, might encourage the irrigation of 50000 ha to accommodate many farmers. However, from an economic and sustainability point of view, it is necessary to carry out further investigation to translate the water-based vulnerability into a yield-based vulnerability. In other words, irrigating 50000 ha instead of 33000 ha could be justified if the increase in total yield from the increase in area by $50 \%$ compensated for the reduction in yield caused by the relative average $7 \%$ water deficit.

\section{Conclusions}

This study provides a simple methodology to assess the performance of the Gash Delta Spate Irrigation System by handling the interdependent relationships among the main variables of the system. The selected criteria are reliability and vulnerability. The criteria of the 3- and 2-year rotation systems were examined at typical values of the intake ratio (IR) and irrigation efficiency (IE), and the result showed that the 3 -year rotation is preferable in the GDSIS. Moreover, the analysis in the feasible ranges of IR and IE revealed that there could be substantial improvement in reliability and vulnerability. This study showed how the rate and amount of change in the selected criteria are affected by individual and concurrent changes in the decision factors. The application of the methodology would provide planners and decision makers with guidance in the selection of a viable rotation system under different irrigation water supply and demand management strategies.

Data availability. Annual flow data of the Gash River measured at the Kassala Bridge gauging station were provided to the authors for this study on the GDSIS from the Gash Agricultural Scheme administrative office and the Gash River training unit, Kassala, Sudan. Currently, the data are not publicly accessible according to the data management policy of the Sudanese government.

Competing interests. The authors declare that they have no conflict of interest.

Special issue statement. This article is part of the special issue "Water security and the food-water-energy nexus: drivers, responses and feedbacks at local to global scales". It is a result of the IAHS Scientific Assembly 2017, Port Elizabeth, South Africa, 10-14 July 2017.

Acknowledgements. The authors would like to thank the Gash Agricultural Scheme administrative office and the Gash River training unit for sharing with us the necessary reports on Gash River flow data. This study was supported by the Grant-in-Aid for Scientific Research (B) from the Japan Society for the Promotion of Research (no. 16H04996, HT).

Edited by: Barry Croke

Reviewed by: three anonymous referees 


\section{References}

Abdelgadir, K.: Evaluation of Field Irrigation of Gash Agricultural Scheme, MSc thesis, Water Management and Irrigation Institute, University of Gezira, Wad Medani, Sudan, 2007.

Anderson, I.: Technical Paper on Main Findings and Recommendations, The Easter Sudan Rehabilitation and Development Fund (ESRDF): GAS Phase II-Design Mission, ESRDF, Sudan, 2011.

Asefa, T., Clayton, J., Adams, A., and Anderson, D.: Performance evaluation of a water resources system under varying climatic conditions: Reliability, Resilience, Vulnerability and beyond, J. Hydrol., 508, 53-65, https://doi.org/10.1016/j.jhydrol.2013.10.043, 2014.

Cole, R.: Land tenure, agricultural labour, drought and food stress in the Gash, Gash Dai and Tokar agricultural areas: Measuring drough and drought impacts in Red Sea Province, Oxfam, Sudan, 1989.

Doorenbos, J. and Kassam, A.: Yield response to water, Rome, FAO, Irrigation and Drainage Paper 33, 1979.

Dudley, N. J., Musgrave, W. F., and Howell, D. T.: Irrigation planning 3 . The best size of irrigation area for a Reservour, Water Resour. Res., 8, 7-17, https://doi.org/10.1029/WR008i001p00007, 1972.

Hashimoto, T., Stedinger, J. R., and Loucks, D. P.: Reliability, Resilience, and Vulnerability Criteria for Water Resource System Performance Evaluation, Water Resour. Res., 18, 14-20, https://doi.org/10.1029/WR018i001p00014, 1982.

IFAD: Gash Sustainable Livelihoods Regeneration Project (GSLRP): Target Group and Project Description, IFAD, Rome, 2004.

IFAD: Gash Sustainable Livelihoods Regeneration Project (GSLRP): Project completion report, Kassala, The republic of Sudan Ministry of Agriculture and Irrigatioin, Sudan, 2012.

IFAD: Republic of The Sudan: Gash Sustainable Livelihoods Regeneration Project, Project Performance Assessment, IFAD, 2014.
Jain, S. K.: Investigating the behaviour of statistical indices for performance assessment of a reservoir, J. Hydrol., 391, 90-96, https://doi.org/10.1016/j.jhydrol.2010.07.009, 2010.

Jain, S. K. and Bhunya, P. K.: Reliability, Resilience and Vulnerability of a Multipurpose Storage Reservoir, Hydrolog. Sci. J., 53, 434-447, https://doi.org/10.1623/hysj.53.2.434, 2008.

James, L.: Principles of farm irrigation systems design, John Wiley and Sons Limited, UK, 1988.

Kirkby, J.: Saving the Gash Delta, Sudan, Land Degrad. Dev., 12, 225-236, https://doi.org/10.1002/ldr.435, 2001.

Kjeldsen, T. R. and Rosbjerg, D.: Choice of reliability, resilence and vulnerability estimators for risk assessments of water resources systems, Hydrolog. Sci. J., 49, 755-767, https://doi.org/10.1623/hysj.49.5.755.55136, 2004.

Loucks, D. P. and van Beek, E.: Water Resources Systems Planning and Management: an introduction to methods, models and applications, UNESCO, Italy, 2005.

Ngirazie, L. A., Bushara, A. I., and Knox, J. W.: Assessing the performance of water user associations in the Gash Irrigation Project, Sudan, Water Int., 1-12, https://doi.org/10.1080/02508060.2015.1072677, 2015.

Swan, C.: The Recorded Behaviour of the River Gash in Sudan, Ministry of Irrigation and Hydro-electric Power, Khartoum, Sudan, 1959.

van Steenbergen, F.: Understanding the sociology of spate irrigation: cases from Balochistan, J. Arid Environ., 35, 349-365, https://doi.org/10.1006/jare.1996.0171, 1997.

van Steenbergen, F., Haile, A. M., Lawrence, P., Salman, M., and Faurès, J.: Guidelines on Spate Irrigation, Rome, FAO, Irrigation and Drainage Paper 65, 2010.

Zimmerman, J.: Irrigation, John Wiley \& Sons, Inc, New York, 1966. 